\title{
The Relationship Between Workers' Health and Night Shift Work in Food Franchise Industry in Kuching, Sarawak, Malaysia
}

\author{
Siew Wui Long ${ }^{1}$, Florianna Lendai Michael ${ }^{2 *}$ and Hana Hamidi ${ }^{3}$ \\ ${ }^{1-3}$ Universiti Malaysia Sarawak, 94300 Kota Samarahan, Sarawak, Malaysia
}

\begin{abstract}
Shift work alters workers exposure to natural and artificial light, sleep patterns, and feeding patterns. Among other working population, shift workers are at a greater risk of developing metabolic impairments over time. Hence, this study aimed to study the relationship between workers' health and night shift work in food franchise industry in Kuching, Sarawak. The independent variables are sleep pattern, mental health, psychological well-being, circadian rhythm, and insomnia, while the dependent variable is night shift work. Questionnaires were distributed using convenience sampling techniques and a total of 59 questionnaires were collected. Pearson Correlations test. showed that there is a significant relationship between workers' health and night shift work. The implications on this research shows that there are more researches on the mitigation of health risk on shift workers.
\end{abstract}

Keywords: Night shift work; sleep pattern; mental health; psychological; circadian rhythm; insomnia

Copyright: This is an open access article distributed under the terms of the Creative Commons Attribution-NonCommercialShareAlike 4.0 International (CC BY-NC-SA 4.0) license which permits unrestricted use, distribution, and reproduction in any medium, for non-commercial purposes, provided the original work is properly cited.

\section{INTRODUCTION}

Shift work is very common in many sectors such as health, transportation, and fire and rescue. Apart from these sectors, there is a rising number of businesses providing 24-

\section{ARTICLE INFO \\ E-mail address: \\ mmflendai@unimas.my (Florianna Lendai Michael) \\ *Corresponding author \\ e-ISSN: $2550-1623$}

Manuscript received: 13 July 2018; Accepted: 27 Sept 2018. Date of publication: 10 Dec 2018 hour services such as fast food restaurants that causes the needs for the employees to work in shift. Hence, this trend leads to an increasing number of shift-workers. According to data from the Occupational Health Survey, 29\% of all U.S. workers in 2010 worked alternative shifts (i.e., not a regular day shift) and $15 \%$ of workers regularly worked a night shift (Kang et al., 2017). In Malaysia, another study conducted by Nilamsari, Prasetya, and Fitriani (2017) that focuses on the impact of shift work leading to high blood pressure. 
Siew Wui Long, Florianna Lendai Michael and Hana Hamidi

International Labour office Geneva (2004) defined working in shifts as "a method of organization of working time in which workers succeed one another at the workplace so that the establishment can operate longer than the hours of work of individual workers." In most cases, shift work is synonymous of odd, flexible, and non-standard working hours. Shift work can be categories into two which is fixed shift system and a rotating shift system.

Fixed shift system mean that employees have a fixed work schedule is a timetable that generally consists of the same number of hours and days worked per week (Doyle, 2017). This means that the workers can work at early hours in the morning, late and night, depending on the arrangement by the organization. Rotating shift system means that the employees are required to work at different times based on a pre-planned pattern (Treadwell, 2017).

There are certain job fields that require the employees to work in shifts. Night shifts are commonly associated with problems and risks to the employees' health. Some employers are not aware of the consequences night shifts bring to employees' health. This is evident by the limited number of studies investigating health issues among employees in the fast food industry. Therefore, this study attempted an insight into what working night shift could do to one's body physically and mentally.

\section{LITERATURE REVIEW}

\section{Night Shift Work}

Due to the development of new technologies and the extension of basic services to general populations, requires continuous human assistance and control over the work processes during the 24 hours day (Costa, 2010). Despite this emerging evidence, labour statistics indicate that the number of people regularly working nights is increasing year-on-year, up 6.9\% between 2007 and 2014, according to the Trades Union Congress (TUC) (Balch, 2015).

\section{Sleep Pattern}

Sleep is an essential prerequisite for human system to function. Unfortunately, sleep problems are critical in the working population (Sergio, 2017) In addition, many Malaysians are caught up in trying to balance work, family and recreation, with sleep time often paying the price (Tan, 2011). When the sleep pattern is off from its normal rhythm, it automatically sets to less sleep and less quality of sleep which contributes to poor performances in doing their tasks (Khan, 2014).

The disturbance of the body's biological clock from a divert sleeping pattern may occur to lots of negative consequences. The circadian rhythm dips for an adult usually starts at 2.00 am to 4.00 am whereas in the afternoon, it would be occurring from $1.00 \mathrm{pm}$ to $3.00 \mathrm{pm}$ (both periods are the strongest derive for an adult to feel sleepy (National Sleep Foundation, 2018). Thus, if an adult could not meet their own needs to sleep at this hour, it would disturb the body's biological clock. This would lead to the adult to feel it hard to go to sleep after they had finished their shift if they try to stay awake during those two crucial periods. In conclusion, sleeping pattern and enough sleeping hours 
for an individual to perform their daily tasks are vital in keeping their cognitive abilities on track.

\section{Mental Health}

Shift work may also be associated with mental health (Kang et al., 2017). Although historically scientific literature on work and health has focused primarily on the occurrence of physical illnesses, in recent years the studies dealing with workers' mental health, or those linking physical and mental issues, have been increasing significantly (Sergio et al., 2017).

Other than that, shift working can be a potential psychosocial stressor. Stress is, however, a difficult concept to define, let alone measure. Many published reports on working hours cite stress as a problem but such reports all too commonly lack scientific rigor, acquiring these data from self- administered questionnaires and case reports (Harrington, 2001). When an individual stay awakes during the whole night and also tries to sleep during the daylight, the hormones and chemicals in the body system are being disrupted due to the contradict sleeping pattern as our hormone usually starts to develop and neutralizes on its own during the night time (Khan, 2014).

\section{Psychological well-being}

Shift work, and night shift in particularly, is one of the most frequent reasons for the disruption because can affect the physical and psychological well-being and negatively condition work performance. However, long hours in the context of a range of other po- tential stressors and their effects on psychological wellbeing (Saunders, 2010). In addition, Natvik et al. (2011) mentioned that shift work can also cause certain issues that decrease wellbeing and happiness.

Besides that, the average of five minutes is considered to represent a pathological level of physiological sleepiness that is seen commonly in patients with sleep disorders such as sleep apnea and narcolepsy (Wright et al., 2013). Therefore, an average to sleep between 5-10 minutes is considered an intermediate level of sleepiness and average latencies greater than 10 minutes are considered to represent low levels of physiological sleepiness.

\section{Circadian Rhythm}

Shift work disorder can increase the risk of mental health problems like depression and this is because of the disruption of the circadian system which regulates the release of different chemicals in the body (National Sleep Foundation, 2017). Circadian rhythm sleep disorders all involve a problem in the timing of when a person sleeps and is awake (American Academy of Sleep Medicine, 2008).

Other than that, Philips (2014) mentioned that shift work sleep disorder occurs when a person's circadian rhythm comes conflicts with their work schedule and causing them to experience insomnia or excessive daytime sleepiness. In addition, Circadian rhythms are synchronized with the earth's rotation by daily adjustments in the timing of the SCN and exposure to stimuli that signal the time of day. However, light, feeding schedules, activity, and the hormone melatonin can also 
affect the circadian timing (Golembek \& Rosentein, 2010). Therefore, shift workers who sleep during the day have a vitamin $\mathrm{D}$ deficiency and more prone to metabolic disorder (Folkard \& Tucker, 2003). Not only that, past researches have also shown that the irregular circadian rhythm also gave a big impact towards the women whereby a significant number of them was diagnosed with breast cancer and pregnancy complications due to the working hours of night shifts and it also affects the men in developing prostate cancer, diabetes, heart disease and obesity (National Sleep Foundation, 2018).

\section{Insomnia}

Insomnia is a common public health problem with an estimated prevalence in both Western and Asian general populations in the range of $11-50 \%$ (Saunders, 2010). Insomnia has also been shown to be related to higher rates of work absenteeism and increased rates of motor vehicle and workplace accidents (von Treuer, Fuller-Tyszkiewicz \& Little, 2014). However, shift work disorder involves insomnia and sleepiness associated with the work schedule (Oaklander, 2014). Besides that, the work schedule can lead to an insomnia different from that of people sleeping by night (Balch, 2015). However, fixed night shifts were associated with higher risks for burnout and mental health problems in women, but the associations disappeared after controlling for insomnia, suggesting that insomnia may play a mediating role (Cheng $\&$ Cheng, 2016). Therefore, the workers may experience insomnia, and may not get enough sleep during the day as the brain remains active, culminating in sleep deprivation (Barnett \& Hyde, 2001). The conceptual framework of this study is shown in Figure 1.

\section{METHODOLOGY}

The research design of this study was quantitative and structured questionnaires were used to as research instrument by using convenience sampling. A total 70 respondents from operational department were involved in this research. The research is conducted in a food franchise industry company located in Kuching, Sarawak for examining the relationship between workers' health and night shift work. using non-probability sampling.

The appropriate sample size was calculated based on the population of production employees using the table generated by Paolo et al., (2016). There were six (6) sections in the questionnaires divided into demographic background, sleep pattern, mental health, psychological, circadian rhythm, and insomnia. A total of 59 out of 70 questionnaires were returned to the researchers. The collected data were analyzed by using Statistical Package for Social Science (SPSS) version 20.0 and the relationship were tested using Pearson Correlation Coefficient Test. There are five (5) independent variables that can be used in this research according to American Psychological Association (2011).

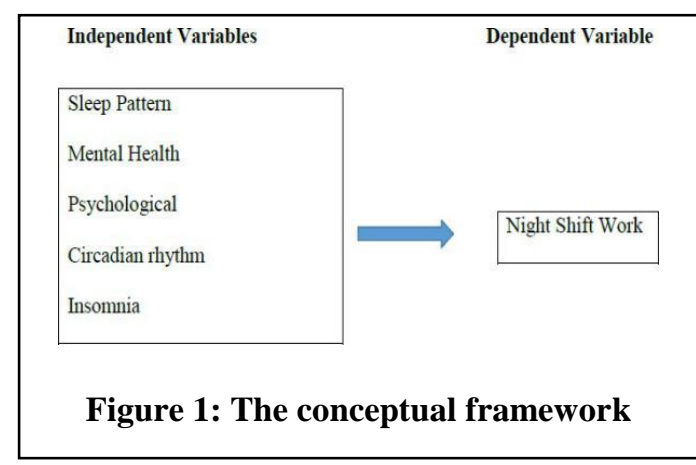


Siew Wui Long, Florianna Lendai Michael and Hana Hamidi

Table 1: Summary of hypothesis testing

\begin{tabular}{lccc}
\hline \multicolumn{1}{c}{ Hypothesis } & P Value & r Value & $\begin{array}{c}\text { Relationship } \\
\text { Strength }\end{array}$ \\
\hline $\begin{array}{l}\text { Ha 1: There is a significant relationship } \\
\text { between sleep pattern and night shift work }\end{array}$ & 0.000 & -0.494 & Negative \\
$\begin{array}{l}\text { Ha 2: There is a significant relationship } \\
\text { between mental health and night shift } \\
\text { work }\end{array}$ & 0.000 & -0.417 & $\begin{array}{c}\text { Moderate } \\
\text { negative }\end{array}$ \\
$\begin{array}{l}\text { Ha 3: There is a significant relationship } \\
\text { between psychological and night shift } \\
\text { work }\end{array}$ & 0.000 & -0.541 & Rejected \\
$\begin{array}{l}\text { Ha 4: There is a significant relationship } \\
\text { between circadian rhythm and night shift } \\
\text { work }\end{array}$ & 0.000 & & Weak negative \\
\hline
\end{tabular}

\section{RESULTS AND DISCUSSIONS}

Based on Table 1, Ha 1 examines the relationship between sleep pattern and night shift work. The result showed a moderate negative relationship on sleep pattern. Hypothesis $\mathrm{Ha} 2$ and Hypothesis $\mathrm{Ha} 5$ tested mental health and circadian rhythm. Both results showed moderate negative relationship with night shift work. Besides, hypothesis Ha5, was used to predict insomnia in night shift work. The result showed a weak negative relationship with night shift work. Hypothesis Ha3 determined the relationship between psychological well-being and night shift work. Ha3 is rejected because the result showed $p$-value is greater than 0.05 . Table 1 presents a summary of the hypothesis testing results examining the relationship between workers' health and night shift work.

The purpose of the study was to examine the relationship between workers' health and night shift work. The results showed the negative relationships between workers' health (sleep pattern, mental health, circadian rhythm and insomnia) and night shift work.
However, this research showed there is no relationship between psychological well-being and night shift work.

The result from this study is consistent with previous studies. As described by Doi (2005), poor sleep quality was proven to be related to perceived health, sick absence, and occupational activities. The irregular working hour seems to exert strong, acute effect on sleep and alertness in relation to night and morning work.

In the study conducted by Åkerstedt $\mathrm{T}$ (2003), the mechanism behind the disturbances is the sleep-interfering properties of the circadian system during day sleep and the corresponding sleep-promoting properties during night work. In accordance with that finding, in the present study work-shift workers had bad quality of sleep and consequently bad functional outcomes.

Night shifts are reported to result in greater loss of total sleep time than evening and slow rotating shift schedules (Kobayashi et al., 2002). The finding of study by Agarwal et al. 
(2014) mentioned that sleep disturbances may leads to poor sleep hygiene, medical conditions, and circadian rhythm disorders which are most common symptoms for scheduled sleep-wake periods and shift work sleep disorder (Belcher, Gumenyek \& Roth, 2015). In fact, sleepiness in the work station may leads to poor concentration on work, accidents and injuries.

High stress of shift work may also result in poor mental health because of the shift work decrease satisfaction of physical and psychical needs (Conway et al. 2008). In a prospective longitudinal study, Berthelsen et al. (2015) examined the impact of different shift types on depression and found that night shifts and rotating shifts were not associated with increased chances of anxiety or depression after 12 months of follow-up (Ruggiero, 2005) and the study found no difference between shift type and level of depression.

However, the study conducted by SaksvikLehouiller et al. (2012) was showed that the relationship between shift work tolerance and depression was best explained by level of hardiness. Hardiness is a general resilience factor influencing how one copes with stress and illness (Storemark et al. 2013) According to Natvik et al. (2011), to determined predictors of depression among shift workers and concluded that the impact of shift work is complex and interrelated with other factors such as morning-ness, sanguinity and hardiness.

According to a study by Paola et al. (2016), the potential impact of this issue on professional well-being is lower job satisfaction. Their study looked at rotated night shift nurses and it was reported that they perceived to have lower job satisfaction. Gu et al. (2015) agreed that rotating night shift work imposes circadian strain and leads to a greater number of physical and psychological symptoms with a higher risk for several chronic diseases than other shift. The result of this study showed there is a significant of relationship that can lead significant relationship between psychological well-being and night shift work.

Tahghighi et al., (2017) found the similar finding and declared that some studies did report negative psychological outcomes for those who working shifts, this was not a consistent finding across all studies (Conway et al., 2008). The current evidence mentioned that shift work may not have the same negative impact on all workers, but it is depending on how they respond to shift work and dependent on other factors.

According to Tahghighi et al., (2017), it is dependent on how much sleep the worker getting, how many days off they had per month, whether they worked part-time of full time, the gender of the worker, and their level of resilience. The result from this study is consistent to existing studies carried by other researchers.

The finding of study conducted by Chang et al. (2011) were explained that every single person has a different adaptability of their circadian rhythm. Workers who do more consecutive night shifts are more likely to adapt their circadian rhythm to the new situation than those who spend a smaller number of night shifts at work (Ferguson et al., 2012). 
According to Kang et al., (2017), night work leads is known to disrupt the body's circadian rhythms, including the sleep- wake pattern. Most prominently, disrupted endogenous melatonin secretion can cause depression, anxiety, and sleep-wake cycle disorders (Rahman et al., 2010). In addition, Driesen et al. (2011) has explained the gender differences is that women may be more vulnerable to the adverse effects of shift work because of their more complex circadian and hormonal rhythms.

Besides, several studies have indicated that night shift work interferes with sleep-wake cycle and reduces the quantity and quality of daily sleep (Ferguson et al., 2012). Hence, night shift results in an approximately 2-hour reduction of individuals' average daily sleep. In addition, the accumulation of lack of enough sleep, in turn, leads to performance decline (Bjorvatn et al., 2006). The result from this study is consistent to existing studies carried by other researchers. In a Japanese study, insomnia was more prevalent among shift workers than among non-shift ones (38\% versus $26 \%$ ); both groups were employed at the same company and assessed using the same instrument and definition of sleep complaints (Nakata et al., 2001). The other study also showed that two rotating shifts, fixed night shift and daytime works were in order of prevalence of sleep complaints and depression in male manual workers (Kobayashi et al., 2002).

The study conducted by Belcher et al. (2015) showed the finding that insomniacs without excessive sleepiness showed more severe impairments than insomniacs who report excessive sleepiness According to Wright et al.
(2013), many shift workers meeting diagnostic criteria for shift work disorder report sleep difficulties consistent with those reported by patients with an insomnia disorder, while others report excessive sleepiness (either alone or in combination with insomnia symptoms).

\section{CONCLUSION}

The purpose of this study was to determine the relationship between employees' health and working night shift among employees in the fast food industry. Employees' mental health, sleep pattern, circadian rhythm and insomnia are found to be related to employees who work night shift. The results are important and useful for the management, $\mathrm{Hu}$ man Resource practitioners and employees when designing work arrangements. In a nutshell, there is a significant relationship between workers' health and night shift work. Hence, this study is beneficial for policymakers in creating a working environment which would reduce risks among employees because of working night shifts.

\section{LIMITATION}

The location focused only on one international fast food restaurant in Kuching. Since the sample size is small, it was difficult to find significant relationships from the data, as statistical tests normally require a larger sample size to ensure a representative distribution of the population and to be considered representative of groups of people to whom results will be generalized or transferred. 


\section{REFERENCES}

Åkerstedt, T. (2003). Shift work and disturbed sleep/wakefulness. Oсcираtional medicine, 53(2), 89-94.

American Academy of Sleep Medicine. (2008). Circadian rhythm sleep disorders. Sleep, 30(11), 484-501.

Balch, O. (2015, October 28). A hard day's night: the hidden health risks of working the night shift. The Guardian.

Barnett, R. C. \& Hyde, J. S. (2001). Women, men, work, and family: an expansionist theory. American Psychologist, 56(10), 781-796.

Belcher, R., Gumenyuk, V., \& Roth, T. (2015). Insomnia in shift work disorder relates to occupational neurophysiological impairment. Journal of Clinical Sleep Medicine, 11(4), 457- 465.

Berthelsen, M., Pallesen, S., Mageroy, N., Tyssen, R., Bjorvatn, B., Moen, B. E. $\&$ Knardahl, S. (2015). Effects of psychological and social factors in shiftwork on symptoms of anxiety and depression in nurses: a 1-year follow-up. Journal of Occupational and Environmental Medicine, 57, 1127-37.

Bjorvatn. B., Stangenes, K., Oyane, N., Forberg, K., Lowden, A., Holsten, F., \& Akerstedt, T. (2006). Subjective and objective measures of adaptation and readaptation to night work on an oil rig in the North Sea. Sleep, 29, 821-9.

Chen, Y. M., Hung, H. C., \& Wu, M.T. (2012). Atypical work schedules are associated with poor sleep quality and mental health in Taiwan female nurses. International Archives of Occupational and Environmental Health, $85,877-884$.

Cheng W. \& Cheng Y. (2016). Night shift and rotating shift in association with sleep problems, burnout and minor mental disorder in male and female employees. Occupational and Environmental Medicine. 74(7), 483-488.

Conway PM, Campanini P, Sartori S, Dotti R, Costa G. (2008). Main and interactive effects of shiftwork, age and work stress on health in an Italian sample of healthcare workers. Applied Ergonomics, 39(5), 630-639.

Doyle, A. (2017, April 17). Types of work schedules. The Balance Careers.

Driesen K, Jansen NW, van Amelsvoort LG, Kant I. (2011). The mutual relationship between shift work and depressive complaints - a prospective cohort study. Scandinavian Journal of Work, Environment and Health. 37(5), 402410.

Ferguson, S. A., Kennaway, D.J., Baker, A., Lamond, N., \& Dawson, D. (2012). Sleep and circadian rhythms in mining operators: limited evidence of adaptation to night shifts. Applied Ergonomics, 43(4), 695-701.

Folkard S., \& Tucker P. (2003). Shift work, safety and productivity. Society of Occupational Medicine, 53(2), 95- 101.

Golombek D.A. \& Rosenstein R.E. (2010). Physiology of circadian entrainment. Physiological Reviews. Retrieved from https://www.ncbi.nlm.nih.gov/ pubmed/20664079 
Golombek, D. A. \& Rosenstein, R. E. (2010). Physiology of circadian entrainment. Physiological Reviews.

International Labour office Geneva. (2004). Shift work. Conditions of Work and Employment Programme. International Labour Organization. Retrieved from http://cite.gov.pt/pt/destaques/ complementosDestqs/integrar_saude.pdf

Kang M.Y., Kwong H.J., Choi K.H., Kang C.W., \& Kim H. (2017). The relationship between shift work and mental health among electronics workers in South Korea: A cross- sectional study. Plos One. 12(11), e0188019.

Khan A. (2014, October 17). How to survive the night shift. Huffpost. Retrieve from https://www.huffpost.com/entry/night-shift-health-survive_n_5985718

Kobayashi, T., Kageyama, T., Kaneko, S., \& Tanaka, M. (2002). A cross sectional survey on insomnia and depressive symptoms in Japanese male shift workers with various shit patterns. The Journal of Yamaguchi Prefectural University of Nursing, 6, 21-7.

Mahathevan, R. (1982). Overview of shift work in developing countries. Journal of Human Ergology. 11, 139-145.

Nakata, A., Haratani, T., Takahashi, M., Kawakami, N., Arito, H., Fujioka, Y. (2001). Job stress, social support at work, and insomnia in Japanese shift workers. Journal of Human Ergology, 30, 203-209.

National Sleep Foundation. (2017). Living and coping with shift work disorder.
Retrieved from https://www.sleepfoundation.org/shift-work/content/living-coping-shift-work-disorder

National Sleep Foundation. (2018). Sleep drive and your body clock. Sleep. Retrieved from https://www.sleepfoundation.org/sleep-topics/sleep-driveand-your-body-clock

Natvik S., Bjorvatn B., Moen B.E., Magerøy N., Sivertsen B., Pallesen S. (2011). Personality factors related to shift work tolerance in two-and three-shift workers. Applied Ergonimics, 42, 719724.

Nilamsari, N., Prasetya, T. A. E., \& Fitriani, N. (2017). Factors Associated With Blood Pressure on Shift Workers and Non-shirft Worker. International Journal of Health Medicine and Current Research, 2(3), 493-502.

Paolo, F., Matteo, G., Luigi, M., Sara, B., Daniela, M., \& Rosaria, L. (2016). The impact of shift work on the psychological and physical health of nurse in a general hospital: a comparison between rotating night shifts and day shifts. Risk Management and Healthcare Policy. 9, 203-211.

Rahman S.A., Marcu S., Kayumov L., Shapiro C.M. (2010). Altered sleep architecture and higher incidence of subsyndromal depression in low endogenous melatonin secretors. European Archives of Psychiatry and Clinical Neuroscience, 260(4), 327-335.

Ruggiero, J. S. (2005). Health, work variables and job satisfaction among nurses. Journal of Nursing Administration, 35, 254-263. 
Siew Wui Long, Florianna Lendai Michael and Hana Hamidi

Saksvik-Lehouillier I., Bjorvatn B., Hetland

H., Sandal G.M., Moen B.E., Magerøy N., Harvey A., Costa G. \& Pallesen S. (2012). Personality factors predicting changes in shift work tolerance: a longitudinal study among nurses working rotating shifts. Work and Stress, 26(2), 143-160.

Saunders, R. (2010, April 22). Shift work and health: what is the research telling us? Institute for Work and Health. Retrieved from https://www.iwh.on.ca/ newsletters/at-work/60/shift-workand-health-what-is-research-telling-us

Sergio A.U., Francisco A., \& Boris, E. C. (2017). Shift work and mental health problems in vulnerable occupational groups. EC Psychology and Psychiatry, 3(2), 25-27.

Tahghighi, M., Rees, C. S., Brown, J. A., Breen, L. J. \& Hegney, D. (2017). What is the impact of night shift work on the psychological functioning and resilience of nurses? An integrative review. Journal of Advanced Nursing, 73(9), 2065-2083.

Tan, S. C. (2011, March 27). Sleep interrupted. The Star Online. Costa, G. (2010). Shift work and health: current problems and preventive actions. Safety and Health at Work, 1(2), 112123. Harrington, J. M. (2001). Health effects of shift work and extended hours of work. Occupational and Environmental Medicine 58, 68-72.

Treadwell, L (2017, July 5). Types of work shift schedules. Career Trend. Retrieved https://careertrend.com/list5790170-types-work-shift-schedules.html

Wright, K. P., Bogan, R. K., \& Wyatt, J. K. (2013). Shift work and the assessment and management of shift work disorder (SWD). Sleep Medicine Reviews, 17, 41-54. 